\title{
Clinical Evaluation of Children with Arthrogryposis Multiplex Congenital in Pakistani Population
}

\author{
MUMTAZ HUSSAIN ${ }^{1}$, SHAHZAD ANVER QURESHI ${ }^{2}$, KHANDAH FISHAN MUMTAZ ${ }^{3}$, QAMAR UZ ZAMAN SHAHZAD ${ }^{4}$ \\ ${ }^{1}$ Associate Professor, Pediatric Orthopedic Surgery Department, The Children's Hospital Lahore. \\ ${ }^{2}$ Fellow Pediatric Orthopedic Surgery, Mayo Hospital Lahore. \\ ${ }^{3,4}$ Assistant Professor Pediatric Medicine, Shalamar Medical \& Dental College Lahore. \\ Correspondence to Dr. Mumtaz Hussain, Email: drmumtazchohan@gmail.com, Cell. 03234200564
}

\begin{abstract}
Background: Arthrogryposis multiplex congenita $(A M C)$ is a rare syndrome with multiple joint contractures. The number of studies which have been previously done on Pakistani population to investigate patients with arthrogryposis is limited.

Aim: This study presents our experience with evaluation and management of children with AMC at The Children Hospital \& the Institute of Child Health, Lahore.

Method: During the period from January 2018 to December 2018, we evaluated 25 children with AMC. The mean age at the time of evaluation was 20.56 months (range, 5 days to 9 years). All of the included patients were evaluated in terms of their clinical state according to selected subjective and objective criteria.

Result: Our results indicate that shoulders were internally rotated (20\%), the elbows were extended (36\%), and the wrists $(76 \%)$ and digits $(56 \%)$ were flexed. Thumb was adducted $(36 \%)$, hands were clawed $(52 \%)$ and palmar crease was absent $(28 \%)$. Hips were found to be dislocated (16\%) and adducted (16\%). Knees having extension contracture (32\%); feet were in equinocavovarus (72\%). Calf muscles were atrophic (56\%).

Conclusion: Our experience shows that the clinical findings are highly variable between families and also within families with AMC. Joint manipulation and casting during the first few months of life may produce considerable improvement. Orthotics may help. Surgery may be needed later, but mobility is rarely enhanced. Muscle transfers may improve function. Many children do remarkably well; two thirds are ambulatory after treatment. A multidisciplinary team evaluation of the child with AMC is recommended for specific diagnosis and planning of treatment.
\end{abstract}

Keywords: Arthrogryposis multiplex congenita (AMC), clinical evaluation.

\section{INTRODUCTION}

The term arthrogryposis is a misnomer; its simple meaning is "stiff joints". We use this term when more than one joint is involved. It's actually a syndrome including different diseases that have common presentation of joint stiffness, visceral and neurological involvement. Very limited work is available in literature regarding its clinical presentation in Pakistan. Its incidence varies from $1 / 3000$ to $1 / 5100$ live births (1). Exact etiology is not known, but it is thought secondary to fetal joint development, due to multiple abnormalities of neurological, muscular, vascular, connective tissue disorders or some environmental factors (2). Multiple types of arthrogryposis are described in literature including, Amyoplasia, distal arthrogryposis and syndromic arthrogryposis. Although association of certain genes with few types of arthrogryposis is established with advances in research in molecular genetics field, but still a lot of thing are still missing in this regard. Gens mutation and their mode of transmission is identified in few types $(3,4)$. Due to this diverse nature of disease and not knowing its exact etiology we could not have a standard treatment protocol for each patient up till now. Each patient varies due to its different presentation and involvement of different organs. So we mainly focus on improvement of functional status of each limb and patient mobility status as a whole. Our goal of this study was to show the typical presentation of arthrogryposis kids in Pakistan, frequency of associations with different organs in same patient.

Received on 23-12-2020

Accepted on 13-04-2021

\section{MATERIAL AND METHOD}

From January 2018 to December 2018, 25 children were identified for arthrogryposis in the Outdoor department of Paediatric Orthopaedic, Children's Hospital and Institute of Child Health Lahore. Our inclusion criteria included all children presenting with joint stiffness present at birth and involving at least two or more joints. Children who have isolated club foot deformity, congenital vertical talus and joint stiffness associated with condition such as cerebral palsy and polio were excluded from the study. After informed consent from the parents, demographic profile (age and sex) was noted. All relevant data relating to family history, pre and perinatal history was taken from mother. Our clinical examination included a Performa noting the general features of a child, his posture, presence of contracture to the specific joint of the limb and spine involvement. Involvement of all four extremities, short limb, clenched fist, compatodectyly, craniofascial abnormalities, opthalmoplegia, claw hand, whistling face, wing like web of knee and elbow and web neck was noted as general features. We also examined the posture of child as having either extended elbows, flexed wrist, ulnar deviation of hand, extended knees, equino-cavo varus feet, congenital vertical talus, atrophic arm and legs and presence or absent of joint crease. Then, we noted the presence of absence of contracture to the specific joint of the upper and lower limb. Spine examination is also performed to note the presence of any deformity like scoliosis. Those who had bilateral involvement were counted as having two separate features. All data was recorded and maintained. Quantitative variables like age (in months), mean $\pm S D$. Qualitative 
variables like gender, birth history, general features, posture and specific joint deformity was presented in the form of frequency and percentages.

\section{RESULTS}

The mean age of the children included in our study was $20.56 \pm 6.78$ months and there were $16(64 \%)$ males and 9 (36\%) females. 12 (48\%) were born via C-sections while 12 $(52 \%)$ were born via SVD. 5 children had brother or sister as having the same symptomatology and cousin marriage was noted in 8 children. Pregnancy related complications like pre-eclampsia, oligo-amnios, bleeding was noted down from mothers and we observed 7 children born with any one of these associated complications. There was no twin pregnancy. Presentation was predominantly cephalic (70\%) as evident on ultrasonography. The delivery was term in 20 children and premature in 5 and the weight was around 2.2 pounds in 14 children. Clinical examination of the child revealed involvement of all four extremities in $17(68 \%)$, short limb in 2(8\%), clenched fist in 9 (36\%), compatodectyly in $14(56 \%)$, craniofascial abnormalities in $3(12 \%)$, opthalmoplegia in $3(12 \%)$, claw hand in $13(52 \%)$, whistling face in $3(12 \%)$, wing like web of knee in $5(20 \%)$ and elbow in $2(8 \%)$ and web neck in $2(12 \%)$. Posture with extended elbow was seen in $9(36 \%)$ children, flexed wrist along with ulnar deviation of hand in $19(76 \%)$. The most common lower limb posture was extended knees (32\%) in the lower limb. Atrophy of leg and forearm was seen respectively in $8(32 \%)$ and $12(48 \%)$. Absent palmer crease was seen in $7(28 \%)$. Joint examination revealed flexion contracture of the elbow, wrist, thumb and fingers as most common in the upper limb. In lower limb, hip involvement as $\mathrm{DDH}(16 \%)$ and adductor contracture (16\%) was seen. Knee as hypertension deformity (44\%) and foot as CTEV (64\%), CVT (52\%) were the notable deformities. In spine, we found scoliosis in 4(16\%) and lordosis 3(12\%) children.

\begin{tabular}{|c|c|c|}
\hline & $\mathbf{n}$ & $\%$ age \\
\hline Age & $\begin{array}{c}20.56 \text { months } \\
\text { (Average) }\end{array}$ & \\
\hline \multicolumn{3}{|l|}{ Gender } \\
\hline Male & 16 & $64 \%$ \\
\hline Female & 9 & $36 \%$ \\
\hline \multicolumn{3}{|l|}{ Clinical History } \\
\hline C- Section & 12 & $48 \%$ \\
\hline \multicolumn{3}{|l|}{ General Features } \\
\hline All four extremeties involved & 17 & $68 \%$ \\
\hline Short limbs & 2 & $8 \%$ \\
\hline Clenched fist & 9 & $36 \%$ \\
\hline Compatodectyly & 14 & $56 \%$ \\
\hline Craniofascial abnormality & 3 & $12 \%$ \\
\hline Ophthalmoplegia & 3 & $12 \%$ \\
\hline Claw hand & 13 & $52 \%$ \\
\hline Whisling face & 3 & $12 \%$ \\
\hline Wing-Like Web of Knee & 5 & $20 \%$ \\
\hline Wing-Like Web of Elbow & 2 & $8 \%$ \\
\hline Web Neck & 3 & $12 \%$ \\
\hline \multicolumn{3}{|l|}{ Posture } \\
\hline Extended Elbow & 9 & $36 \%$ \\
\hline Flexed wrist & 19 & $76 \%$ \\
\hline Ulnar Deviation of Hand & 19 & $76 \%$ \\
\hline
\end{tabular}

\begin{tabular}{|c|c|c|}
\hline Knee Extended & 8 & $32 \%$ \\
\hline Equino-cavo-varus foot & 18 & $72 \%$ \\
\hline Atrophic arms & 8 & $32 \%$ \\
\hline Atrophic legs & 12 & $48 \%$ \\
\hline Absent joint crease & 13 & $52 \%$ \\
\hline CVT & 13 & $52 \%$ \\
\hline \multicolumn{3}{|l|}{ Shoulder } \\
\hline Internal Rotation Contracture & 5 & $20 \%$ \\
\hline \multicolumn{3}{|l|}{ Elbow } \\
\hline Flexion Contracture & 1 & $4 \%$ \\
\hline Extension Contracture & 2 & $8 \%$ \\
\hline \multicolumn{3}{|l|}{ Wrist } \\
\hline Extension Contracture & 2 & $8 \%$ \\
\hline Flexion Contracture & 11 & $44 \%$ \\
\hline Absent palmar crease & 7 & $28 \%$ \\
\hline \multicolumn{3}{|l|}{ Thumb } \\
\hline Opponence Contracture & 9 & $36 \%$ \\
\hline \multicolumn{3}{|l|}{ Fingers } \\
\hline Flexion Contracture & 14 & $56 \%$ \\
\hline \multicolumn{3}{|l|}{ Hip } \\
\hline Dislocation (DDH) & 4 & $16 \%$ \\
\hline Adduction Contracture & 4 & $16 \%$ \\
\hline \multicolumn{3}{|l|}{ Knee } \\
\hline Hyperextension & 11 & $44 \%$ \\
\hline Flexion Contracture & 5 & $20 \%$ \\
\hline Extension Contracture & 5 & $20 \%$ \\
\hline \multicolumn{3}{|l|}{ Feet } \\
\hline CTEV & 16 & $64 \%$ \\
\hline Calf Atrophy & 14 & $56 \%$ \\
\hline Absent Flexion Crease & 5 & $20 \%$ \\
\hline Pes Planus (Bilateral) & 2 & $8 \%$ \\
\hline Hallux Valgus & 2 & $8 \%$ \\
\hline \multicolumn{3}{|l|}{ Spine } \\
\hline Scoliosis & 4 & $16 \%$ \\
\hline Lordosis & 3 & $12 \%$ \\
\hline
\end{tabular}

\section{DISCUSSION}

Arthrogryposis is not a diagnosis rather it is a group of clinical findings. According to some of studies it is present in more than 100 syndromes. Regarding epidemiology its prevalence has very diversity from $1 / 3000$ to $1 / 56000$ live births. This diversity may be due to lack of a clear-cut diagnostic criterion that is unfortunately not available up till now. Arthrogryposis is evident at birth and mostly it involves all four limbs, but it can present with involvement of a single limb, although it is rare presentation. Most common deformity is clubfoot. Almost $90 \%$ cases present with this problem. This deformity may be due under-developed or absent muscles or due to fibrosed tissues of joint, exact cause not known. This deformity is resistant to routine Ponsity casting and usually need more number of casts than needed in idiopathic clubfoot. Other foot deformities include mainly cavus, equinus, calcanio-valgus or any combination. Hip involvement is also very common. Scissoring or hip adduction contracture can leads to hip subluxation and ultimately hip dislocation. Passive hip abduction is achievable in majority of cases at the time of birth. If hip is located then flexion-abduction-external rotation contracture is common, but if hip is dislocated then it is in position of fixed adduction. Shoulders also present usually in adduction and internal rotation contracture, with limited range of motion. Elbow presented with flexion or 
extension contracture and forearm in pronated position. Wrist in flexion attitude along with flexion contracture of all digits at PIPs and DIPs joints. Thumb in palm deformity is common. Spine deformities are common and incidence varies between $2.5 \%$ to $65.9 \%(10)$. Anomalies other than bone and joints include; characteristic facial features, rounded expressionless face ${ }^{11}$, hemengiomatous spot on face, genito-urinary, gastrointestinal, cardio-vascular or maxillary abnormality (microgonathia) ${ }^{12}$. Incidence of these extra-osseous features are comparatively rare.

There are many types of arthrogryposis but congenital amyoplasia is most frequent type (one third of cases) ${ }^{8,13}$. It is characterized by symmetrical muscle hypoplasia and associated distal limb deformities. Muscles are usually replaced by fibers and adipose tissue. Distal arthrogryposis is a particular type of arthrogryposis affecting hand and feet $^{14}$.

Exact etiology of arthrogryposis is not known, but there are few findings. Absence of fetal movements, fetal akinesia appears to be basic cause. Earlier this happen in intrauterine life, more severe the presentation at birth ${ }^{3}$. It is observed that joint development remains normal during embryogenesis, but due to increase thickening of joint capsule and associated defective muscles, joint stiffness is exaggerated $^{3,15}$. Majority of cases of Arthrogryposis have associated neurological abnormalities (90\%) and most common is decrease in cells in the anterior horn of spinal $\operatorname{cord}^{16}$. Other neurological association includes peripheral neuropathy, neuro-muscular junction transmission failure ${ }^{3,17}$. Some studies correlate arthrogryposis with maternal and metabolic abnormalities ${ }^{3,18}$. Diagnosis of classification of arthrogryposis is important for better treatment and prevention of recurrence ${ }^{3,4}$. Pre-natal screening can detect joint stiffness, presence of deformities and decrease fetal movements, oligohydramnion, polyhydromnion by Ultra sonography, even at 16th to 18th week of gastation ${ }^{6,19}$. Nuchal translucency detection is possible in third trimester ${ }^{20}$. Prenatal diagnosis can help to manage delivery at better place so to reduce expected birth complications at time of delivery.

Main things that help to maintain and increase joint movement are rehabilitation, orthosis and surgery ${ }^{4}$. Rehabilitation give good results if started at birth because joints are very flexible at that time. But it must be gentle to prevent fracture and plastic deformation of bones should started at birth is very important to increase and maintain joint movements. Casting can help to correct deformities of feet and hands. In upper limb we mainly concerned regarding functional capability of patient like eating, cleaning, washing, holding crutches etc. so role occupational therapy is very important. Role of surgery for upper limb is very rare, as many patients become able to perform their daily activity of living by alternate movements of upper limb21,22.

Surgery is more common for lower limb deformities. Hip dislocation or even subluxation is indication of surgery, open reduction or soft tissue contracture releases for correction of hip subluxation, stiffness, avascular necrosis of head of femer ${ }^{9,23}$. For genu recurvatum casting gives better results if started in early life but surgical release of soft tissue or even osteotomy can be an option for resistant cases. If hip and knee both effected then treatment started addressing knee first $^{24}$. To address knee flexion contracture, serial knee extension casting gives good results but if contracture is more severe then surgical releases of hamstrings and posterior capsulotomy of knee joint or even femoral shortening and gradual correction by using illizrov, can be an option ${ }^{25,26}$.

For clubfoot deformity in arthogryposis, Ponsity casting should be first choice. These feet are more resistant as compared to idiopathic clubfoot $^{27}$. Even though it involves more number of casts, relapses and increase number of other complications; but surgery should be last option. Surgical releases should be thorough so to prevent recurrences as it would leads to stiff foot and more chances of vascular injury in subsequent surgery ${ }^{28}$. Severe deformed foot can be corrected by illizrov fixator or by talectomy procedure ${ }^{29}$. Surgical release of Cavus foor also have good results ${ }^{30}$. Arthrogryposis patients also need special precautions regarding anesthesia. Direct laryngoscopy and Intubation can be difficult due to small jaw or narrow airways ${ }^{31}$. These patients are sometime more sensitive to respiratory depression effect of analgesic drugs. Breathing difficulties can be due to myopathy, pulmonary hypoplasia or spinal deformity ${ }^{11}$. PODCl score is one of good tool to assess the function, happiness and pain in children with limitations in joint mobility ${ }^{5}$. The prognosis depends mainly on etiology diagnosis and proper rehabilitation ${ }^{22}$. Congenital stiffness in distal arthrogryposis is easier to treat than in amyoplasia that usually require surgeries.

\section{CONCLUSION}

As the causes of arthrogryposis are not curable, the goal of support is to improve the functions of bulation and prehension and acquire the maximum of self- nomie to facilitate social integration and ensure education normal. The role of the family for the integration of the child in society is very important. Psychological care logic of the parents is part of the treatment because they must be able to withstand a long treatment starting from birth and continues throughout growth.

\section{REFERENCES}

1. Darin N, Kimber E, Kroksmark AK, et al. Multiple congenital contractures: birth prevalence, etiology, and outcome. J Pediatr 2002; 140: 61-7.

2. Haliloglu G, Topaloglu H. Arthrogryposis and fetal hypomobility syndrome. Handb Clin Neurol 2013; 113: 1311-9.

3. Hall JG. Arthrogryposis (multiple congenital contractures): diagnostic approach to etiology, classification, genetics and general principles. Eur J Med Genet 2014; 57: 464-72.

4. Bamshad M, Van Heest AE, Pleasure D. Arthrogryposis: a review and update. J Bone Joint Surg 2009; 91: 40-6 .

5. Daltroy LH, Liang MH, Fossel AH, et al. The POSNA pediatric musculoskeletal functional health questionnaire: report on reliability, validity, and sensitivity to change. Pediatric Outcomy Instrument Development Group. Pediatric Orthopedic Society of North America. J Pediatr Orthop 1998; 18: 561-71.

6. Hoff JM, Loane M, Gilhus NE, et al. Arthrogryposis multiplex congenita: an epidemiologic study of nearly 9 million births in 24 EUROCAT registers. Eur J Obstet Gynecol Reprod Biol 2011; 159: 347-50.

7. Guidera KJ, Drennan JC. Foot and ankle deformities in arthrogryposis multiplex congenita. Clin Orthop 1985; 194: 93-8. 
8. Eriksson M, Gutierrez-Farewik E, Broström E, et al. Gait in children with arthrogryposis multiplex congenita. J ChildOrthop 2010; 4: 21-31.

9. Akazawa H, Oda K, Mitani S, et al. Surgical management of hipdislocation in children with arthrogryposis multiplex congenita. J Bone Joint Surg 1998; 80: 636-40 .

10. Campbell RM. Spine deformities in rare congenital syndromes.Spine 2009; 34: 1815-27.

11. Martin S, Tobias JD. Perioperative care of the child witharthrogryposis. Pediatr Anesth 2006; 16: 31-7.

12. Obarski TP, Fardal PM, Bush CR, et al. Stenotic aortic and mitral valves in three adult brothers with arthrogryposis multiplex congenita. Am J Cardiol 2005; 96: 464-6.

13. Fassier A, Wicart $P$, Dubousset $J$, et al. Arthrogryposis multiplex congenita. Long-term follow-up from birth until skeletal ma-turity. J Child Orthop 2009; 3: 383-90 .

14. Bamshad M, Jorde LB, Carey JC. A revised and extended classi-fication of the distal arthrogryposes. Am J Med Genet1996; 65: 277-81.

15. Swinyard CA. Concepts of multiple congenital contractures (arthrogryposis) in man and animals. Teratology 1982; 25: 247-58.

16. Vuopala K, Ignatius J, Herva R. Lethal arthrogryposis with anterior horn cell disease. Hum Pathol 1995; 26: 12-9 .

17. Vajsar J, Sloane A, MacGregor DL, et al. Arthrogryposis multiplex congenita due to congenital myasthenic syndrome.Pediatr Neurol 1995; 12: 237-41.

18. Livingstone IR, Sack GH. Arthrogryposis multiplex congenita occurring with maternal multiple sclerosis. Arch Neurol 1984; 41: 1216-7.

19. Lin IW, Chueh HY, Chang SD, et al. The application of threedimensional ultrasonography in the prenatal diagnosis of arthrogryposis. Taiwan J Obstet Gynecol 2008; 47: 75-8.

20. Dane B, Dane C, Aksoy F, et al. Arthrogryposis multiplex congenita: analysis of twelve cases. Clin Exp Obstet Gynecol 2009; 36: 259-62.
21. Martin G, Perrot P, Duteille F. Treatment of a congenital deficit bilateral elbow flexion in a child classified as arthrogrypose. Chir Main 2009; 28: 116-9.

22. Mennen $U$. Early corrective surgey of the wrist and elbow in arthrogryposis multiplex congenita. J Hand Surg 1993; 18B:304-7 .

23. Asif $S$, Umer M, Beg R, et al. Operative treatment of bilateral hip dislocation in children with arthrogryposis multiplex congenita. J Orthop Surg 2004; 12: 4-9 .

24. Johnston CE. Simultaneous open reduction of ipsilateral congenital dislocation of the hip and knee assisted by femoral diaphyseal shortening. J Pediatr Orthop 2011; 31: 732-40 .

25. Murray C, Fixsen JA. Management of knee deformity in classical arthrogryposis multiplex congenita (amyoplasia congenita). J Pediatr Orthop B 1997; 6: 186-91.

26. Van Bosse H, Feldman D, Anavian J, et al. Treatment of knee flexion contractures in patients with arthrogryposis. J PediatrOrthop 2007; 27: 930-7.

27. Janicki JA, Narayanan UG, Harvey B, et al. Treatment of neuromuscular and syndrome-associated (nonidiopathic) clubfeet using the Ponseti method. J Pediatr Orthop 2009; 29: 393-7 .

28. Widmann RF, Twee T, Burke SW. Radical soft-tissue release of the arthrogrypotic clubfoot. J Pediatr Orthop B 2005; 14: $111-5$.

29. D'Souza H, Aroojis A, Chawara GS. Talectomy in arthrogryposis: analysis of results. J Pediatr Orthop 1998; 18: 760-4.

30. Angsanuntsukh C, Oto M, Holmes L, et al. Vertical congenital talus in multiple pterygium syndrome. J Pediatr Orthop2011; 31: 564-9.

31. Nguyen NH, Morvant EM, Mayhew JF. Anesthesic management for patients with arthrogryposis multiplex congenita and severe micrognathia: case reports. J Clin Anesth 2000; 12: 227-30. 